\title{
Composite bilateral internal thoracic artery grafts: Y not
}

\author{
Umberto Benedetto, $\mathrm{MD}, \mathrm{PhD},{ }^{\mathrm{a}}$ and Mario F. Gaudino, $\mathrm{MD}^{\mathrm{b}}$
}

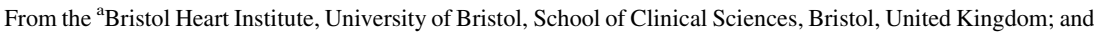
${ }^{\mathrm{b}}$ Department of Cardiothoracic Surgery, Weill Cornell Medical College, New York, NY. Disclosures: Authors have nothing to disclose with regard to commercial support.

Received for publication Jan 18, 2017; accepted for publication Jan 28, 2017; available ahead of print Feb 24, 2017.

Address for reprints: Umberto Benedetto, MD, PhD, Bristol Heart Institute, University of Bristol, Senate House, Tyndall Ave, Bristol, BS8 1TH, United Kingdom (E-mail: Umberto.benedetto@hotmail.com). J Thorac Cardiovasc Surg 2017;153:1117 $0022-5223 / \$ 36.00$

Copyright (C) 2017 by The American Association for Thoracic Surgery http://dx.doi.org/10.1016/j.jtcvs.2017.01.033
}

Despite increasing interest for additional arterial conduits during coronary artery bypass graft surgery, the quest for additional arterial conduits continues. The Arterial Revascularization Trial (ART) enrolled 3102 patients undergoing coronary artery bypass graft surgery for multivessel disease to compare survival after bilateral internal thoracic artery (BITA) over single internal thoracic artery grafting, and mid-term results (5 years) recently have been reported with no difference between the groups. ${ }^{1}$ A possible explanation for the equipoise between the 2 groups is that the increased technical complexity of BITA grafts can result in increased rates of graft failure. In particular, composite BITA grafts (so-called Y-grafts) may be more prone to competitive flow and subsequent graft failure compared with in situ BITA grafts. ${ }^{2}$ Whether BITA graft configuration influences clinical outcomes, however, remains unclear. Yanagawa and colleagues ${ }^{3}$ compared Y-grafts versus in situ BITA grafts configuration pooling data from 2 randomized controlled trials and 6 observational studies. They found that the use of Y-graft was associated with greater distal anastomoses compared with the in situ graft, and there were no differences in perioperative or longer-term cardiovascular outcomes between the 2 groups.

The authors should be congratulated for their extensive literature search and sophisticated statistical analysis. Their findings support previous angiographic follow-up studies that showed excellent patency rates using both BITA graft configurations. ${ }^{4}$

It should be highlighted, however, that most of the studies included were largely underpowered to detect significant differences in hard clinical endpoints, and only 2 studies presented a follow-up longer than 5 years. ${ }^{3}$ Moreover, the magnitude of the vascular bed for runoff, which is influenced by the degree of target stenosis, the vessel diameter, and diffuseness of disease, significantly influences the patency of arterial grafts, but this aspect was not analyzed. ${ }^{5}$

Finally, it remains unclear to what extent graft failure affects clinical outcome. Not all targets and relative grafts are of equal importance, with significant numbers of

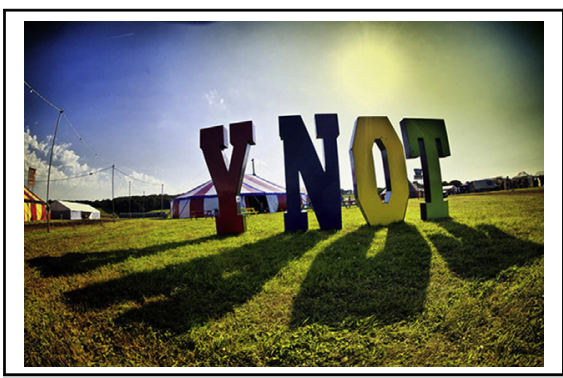

No current evidence supports the perceived increased risk with Y-grafts over in situ bilateral internal thoracic artery graft configuration.

\section{Central Message}

Every effort should be made to ensure wellfunctioning bilateral internal thoracic artery grafts before leaving the operating room, regardless of the configuration adopted.

See Article page 1108 .

asymptomatic graft failures reported. ${ }^{6}$ Therefore, comparable (mid-term) outcomes from Y- and in situ BITA grafts do not automatically translate into comparable patency rate.

Every effort should be made to ensure well-functioning BITA grafts before leaving the operating room regardless of the configuration adopted. Accordingly, intraoperative flow measurement through newly constructed grafts should be mandatory in modern coronary artery bypass grafting to improve surgical outcomes.

\section{References}

1. Taggart DP, Altman DG, Gray AM, Lees B, Gerry S, Benedetto U, et al; ART Investigators. Randomized Trial of Bilateral versus Single Internal-Thoracic-Artery Grafts. N Engl J Med. 2016;375:2540-9.

2. Kang CH, Kim KB, Park CS, Paeng JC, Lee DS. Improvement of myocardia stress perfusion after off-pump revascularization using bilateral internal thoracic in situ grafts versus Y-composite grafts. Ann Thorac Surg. 2005;79:93-8.

3. Yanagawa B, Verma S, Jüni P, Tam DY, Mazine A, Puskas JD, et al. A systematic review and meta-analysis of in situ versus composite bilateral internal thoracic artery grafting. J Thorac Cardiovasc Surg. 2017;153:1108-16.e16.

4. Glineur D, Hanet C, Poncelet A, D'hoore W, Funken JC, Rubay J, et al. Comparison of bilateral internal thoracic artery revascularization using in situ or Y graft configurations: a prospective randomized clinical, functional, and angiographic midterm evaluation. Circulation. 2008;118(14 suppl):S216-21.

5. Hayward PA, Buxton BF. Contemporary coronary graft patency: 5-year observational data from a randomized trial of conduits. Ann Thorac Surg. 2007; 84:795-9.

6. Lopes RD, Mehta RH, Hafley GE, Williams JB, Mack MJ, Peterson ED, et al. Project of Ex Vivo Vein Graft Engineering via Transfection IV (PREVENT IV) Investigators. Relationship between vein graft failure and subsequent clinical outcomes after coronary artery bypass surgery. Circulation. 2012;14:749-56. 